\section{In vitro reparative dentin: a biochemical and morphological study}

\author{
G. Teti, ${ }^{1}$ V. Salvatore, ${ }^{1}$ A. Ruggeri, ${ }^{1}$ \\ L. Manzoli, ${ }^{1}$ M. Gesi, ${ }^{2}$ G. Orsini, ${ }^{3}$ \\ M. Falconi ${ }^{1}$
}

'DIBINEM - Department of Biomedical and Neuromotor Sciences, University of Bologna

${ }^{2}$ Department of Translational Research and New Technologies in Medicine and Surgery, University of Pisa ${ }^{3}$ Department of Clinical Sciences and Stomatology, Polytechnic University of Marche, Ancona, Italy

\section{Abstract}

In this study, starting from human dental pulp cells cultured in vitro, we simulated reparative dentinogenesis using a medium supplemented with different odontogenic inductors. The differentiation of dental pulp cells in odontoblast-like cells was evaluated by means of staining, and ultramorphological, biochemical and biomolecular methods. Alizarin red staining showed mineral deposition while transmission electron microscopy revealed a synthesis of extracellular matrix fibers during the differentiation process. Biochemical assays demonstrated that the differentiated phenotype expressed odontoblast markers, such as Dentin Matrix Protein 1 (DMP1) and Dentin Sialoprotein (DSP), as well as type I collagen. Quantitative data regarding the mRNA expression of DMP1, DSP and type I collagen were obtained by Real Time PCR. Immunofluorescence data demonstrated the various localizations of DSP and DMP1 during odontoblast differentiation. Based on our results, we obtained odontoblast-like cells which simulated the reparative dentin processes in order to better investigate the mechanism of odontoblast differentiation, and dentin extracellular matrix deposition and mineralization.

\section{Introduction}

In mature teeth, odontoblasts are highly specialized cells, aligned in a single layer at the edge of the dental pulp and are responsible for the secretion and mineralization of the dentin extracellular matrix. ${ }^{1,2}$ They originate from mesenchymal papilla cells, and their differentiation implies different successive steps including withdrawal from the cell cycle, cellu- lar polarization, ${ }^{3}$ formation of a cellular process, synthesis and secretion of type I collagen (the main constituent of dentin extracellular matrix) and several noncollagenous proteins (NCPs). ${ }^{1,4,5}$ Of these, dentin sialoprotein (DSP), dentin matrix protein (DMP1), dentin phosphoprotein (DPP), osteocalcin (OC), and osteopontin (OPN) are commonly expressed by differentiated odontoblasts. ${ }^{6-8}$ Although much is known about the morphology of odontoblast cells, their cell modification during dentinogenesis and mineral deposition, their phenotypic expression, and the molecular mechanisms affecting the secretory activity of mature human odontoblasts as a response to external stimuli are still not well understood.

After treatment of deep caries, odontoblast cells die and a new generation of odontoblastlike progenitor cells may differentiate from progenitor cells within the pulp, and secrete a reparative dentin matrix..$^{9,2}$ Odontoblast differentiation during tooth repair undergoes related but different processes as compared to tooth embryonic dentinogenesis ${ }^{10,11}$ and different growth factors, such as transforming growth factors (TGFs), fibroblast growth factors (FGFs) and insulin-like growth factors (IGFs) have been suggested to be mediators of epithelium-mesenchyme interactions. ${ }^{12,13}$

The present study developed an experimental protocol for the in vitro differentiation of human odontoblast-like cells, in order to elucidate the functional mechanisms involved in human reparative dentin formation under physiological and pathological conditions. The in vitro cell culture system proposed is based on the isolation and cell culture of human dental pulp cells (hDPCs). In our odontoblast differentiation model, hDPCs were differentiated in vitro with odontogenic factors, such as TGFbetal, $\beta$-glycerophosphate ( $\beta \mathrm{GP})$, ascorbic acid and dexamethasone for $1,7,14$, and 21 days. Compared to the scientific literature which described the synthesis of reparative dentin based on adding only $\beta \mathrm{GP}$ and ascorbic acid to the medium, ${ }^{1}$ the novelty of our protocol consisted in the combination of all the osteogenic factors ( $\beta \mathrm{GP}$, ascorbic acid and dexamethasone) $)^{1,14}$ with the TGF $\beta 1$. The TGF- $\beta 1$ is one of the most abundant cytokines found in bone matrix and is a potent stimulator of tissue regeneration and a fibrogenic mediator, ${ }^{15}$ and its ability to promote fibroblastic differentiation has already been investigated in other systems. ${ }^{16,17}$ We chose TGF-betal treatment in order to significantly increase the differentiative potential of pulp cells and to accelerate the regeneration of functional dentin. Alizarin red staining, ultrastructural morphological analysis by electron microscopy, and biochemical assays of type 1 collagen, and DMP1 and DSP expressions were carried out to demonstrate the odontoblast phenotype. The very sensitive
Correspondence: Prof. Mirella Falconi,

DIBINEM - Department of Biomedical and Neuromotor Sciences, University of Bologna, via Irnerio 48, 40126 Bologna, Italy.

Tel. +39.051.2091511 - Fax: +39.051.251735

E-mail:mirella.falconi@unibo.it

Key words: dental tissue, in vitro differentiation, DMP1, DSP, type I collagen.

Contributions: GT, study conception and design, experiments performing; MF, study conception and design, data analysis and interpretation, article drafting and critical revision and final version approval; VS, experiments performing; LM, GO, MG, data analysis and interpretation; AR, article drafting and critical revision; LM, article final version approval.

Acknowledgments: this study was supported by the Italian Ministry of Research and Technology (MURST) with an FIRB grant (RBAP10 MLK7_005) and a PRIN 2009 grant.

Received for publication: 24 May 2013

Accepted for publication: 27 June 2013.

This work is licensed under a Creative Commons Attribution NonCommercial 3.0 License (CC BYNC 3.0).

(C) Copyright G. Teti et al., 2013

Licensee PAGEPress, Italy

European Journal of Histochemistry 2013; 57:e23 doi:10.4081/ejh.2013.e23

Real Time PCR technique was then used to validate and verify the above mentioned analyses while immunofluorescence was carried out to demonstrate the various localizations of DMP1 and DSP proteins during the differentiation process.

\section{Materials and Methods}

\section{Human dental pulp cells culture}

The hDPCs were obtained from the molars of healthy donors (from 16 to 30 years of age), following a protocol approved by the University of Bologna. Informed consent was obtained from all patients. The pulp was carefully minced and collected in $60 \times 15 \mathrm{~mm}$ cell-cultured dishes in Dulbecco's Modified Eagle Medium (DMEM, Gibco, Life Technologies, Monza, Italy) supplemented with 10\% Fetal Bovine Serum (FBS, Gibco, Life Technologies) and $1 \%$ penicillin/streptomycin, and was then incubated at $37^{\circ} \mathrm{C}$ in a humidified atmosphere of $5 \% \mathrm{CO}_{2}$. The cells were subcultured once a week using $1 \%$ trypsin (Gibco, Life Technologies), expanded in new T25 flasks 
and maintained at $37^{\circ} \mathrm{C}$ in a humidified atmosphere of $5 \% \mathrm{CO}_{2}$. Cells from passages 2 to 10 were utilized for the experiments described.

\section{Differentiation of odontoblast-like cells}

To induce odontoblast differentiation, DMEM medium was replaced with Modified Eagle Medium (MEM, Gibco, Life Technologies) supplemented with 10\% FBS and $1 \%$ penicillin/streptomycin and with 0.1 $\mu \mathrm{M}$ dexamethasone, $0.1 \% \beta \mathrm{GP}, 50 \mu \mathrm{g} / \mathrm{mL}$ ascorbic acid and $10 \mathrm{ng} / \mathrm{mL}$ TGF- $\beta 1$. The cells were induced to odontoblast differentiation for $24 \mathrm{~h}$, 7,14 , and 21 days corresponding to the experimental points of D1, D7, D14, D21.

Control samples (CTR) consisted of hDPCs grown in MEM medium for the same period of time without any odontoblast differentiation factors.

\section{Alizarin red staining}

Human DPCs were seeded into a 12 -well plate at a concentration of 20,000 cells/mL and induced to odontoblastic differentiation as previously described. At the end of each treatment, the samples were washed twice in phosphate buffer saline (PBS), fixed with $4 \%$ paraformaldehyde in PBS for $30 \mathrm{~min}$ at $4^{\circ} \mathrm{C}$ and stained with $2 \%$ Alizarin red in water $(\mathrm{pH}$ 4.1) for $15 \mathrm{~min}$ at room temperature (RT).

\section{Transmission electron microscopy}

At the end of each treatment, the hDPCs were fixed in $2.5 \%$ glutaraldehyde in $0.1 \mathrm{M}$ phosphate buffer for $2 \mathrm{~h}$ at $4^{\circ} \mathrm{C}$. After washes in $0.15 \mathrm{M}$ phosphate buffer, the samples were post-fixed in $1 \% \mathrm{OsO}_{4}$ in $0.1 \mathrm{M}$ phosphate buffer for $1 \mathrm{~h}$ at $4^{\circ} \mathrm{C}$ and dehydrated in a graded series of acetone. The samples were embedded in Epon resin (Sigma Aldrich, St. Louis, MO, USA), and ultrathin sections were counterstained with uranyl acetate and lead citrate. The sections were observed under a Philips CM10 transmission electron microscope (FEI Company, Eindhoven, The Netherlands) and the images were digitally captured by a SIS Megaview III CCD camera (FEI Company,).

\section{Protein extraction and western blot analysis}

At each experimental point, the cell pellets were lysed for 30 min using a cell extraction buffer (Invitrogen, Life Technologies) supplemented with a protease inhibitor cocktail (Sigma Aldrich), $1 \mathrm{mM}$ phenylmethylsulfonyl fluoride (PMSF) and 0.15\% $\beta$-mercaptoethanol (Fluka, Sigma Aldrich). The samples were centrifuged at $14,000 \mathrm{rpm}$ for $10 \mathrm{~min}$ a $4^{\circ} \mathrm{C}$ and the total protein amounts were assayed using
Breadford reagent (Sigma Aldrich). Twenty $\mu g$ of total protein were resolved on NuPAGE ${ }^{\circledR}$ SDS-PAGE pre-cast Gels (4-12\%) (Invitrogen, Life Technologiesy), and the protein was transferred to a nitrocellulose membrane (GE Healthcare Europe $\mathrm{GmbH}$, Milan, Italy), blocked with $2.5 \%$ bovine serum albumin (BSA) $/ 2.5 \%$ no fat dry milk (Sigma Aldrich), and immunolabeled with anti-DMP1 1:500 in blocking reagent (Abcam, Cambridge, UK),
anti-DSP 1:100 in blocking reagent (Santa Cruz Biotechnologies, Santa Cruz, CA, USA), anti-procollagen 1 type I 1:500 in blocking reagent (Santa Cruz Biotechnology) and anti$\beta$ tubulin 1:10000 in blocking reagent (Sigma Aldrich) for $2 \mathrm{~h} 30 \mathrm{~min}$ at RT. The bands were visualized by an ECL Advanced TM Western blotting detection kit (GE Healthcare Europe $\mathrm{GmbH}$ ) and the images were recorded using a Kodak digital image station (Eastman Kodak,
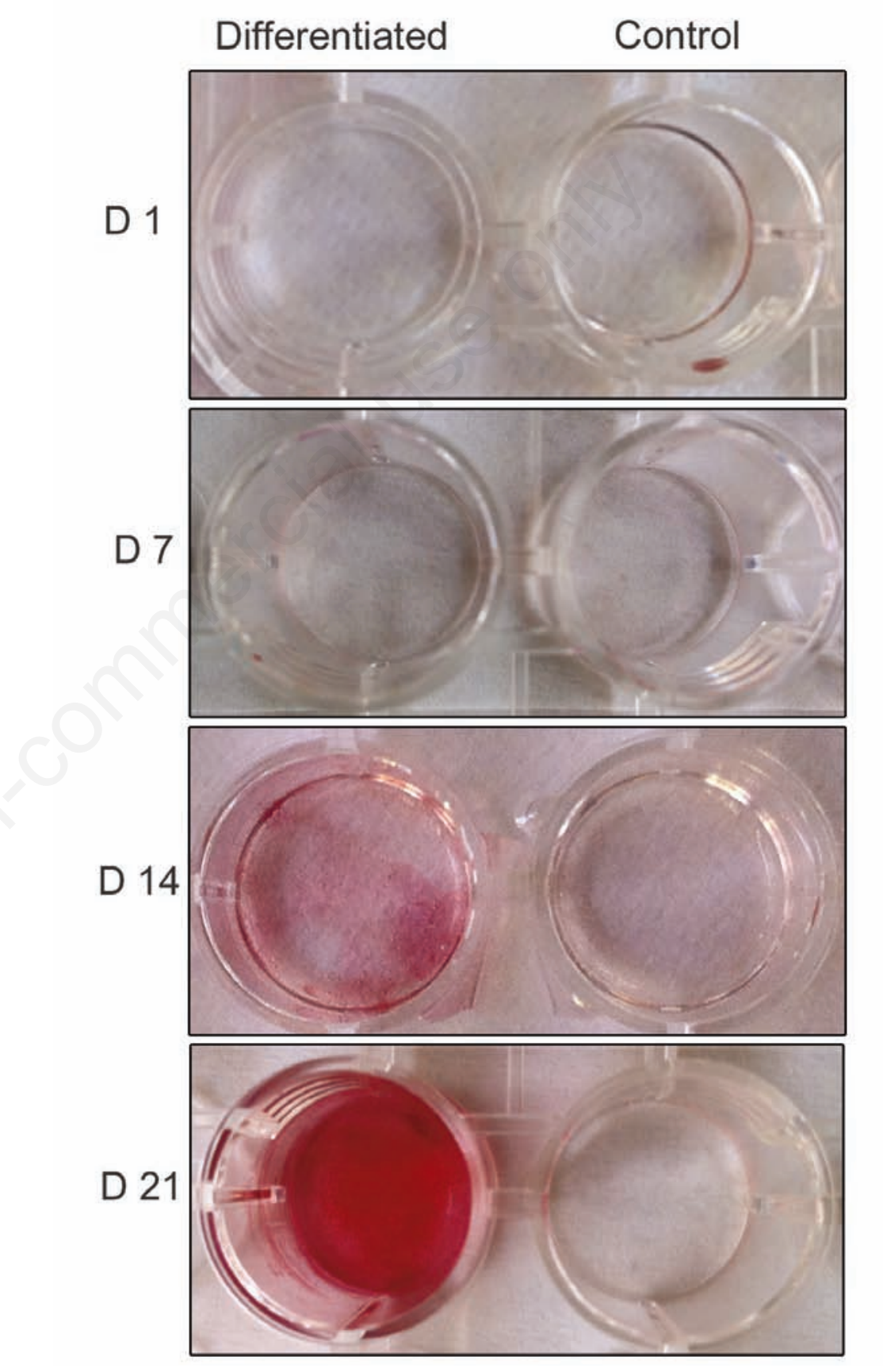

Figure 1. Alizarin red staining demonstrating the calcification nodule formation in the
control and the differentiated samples after 1 (D1), 7 (D7), 14 (D14) and 21 (D21) days

Figure 1. Alizarin red staining demonstrating the calcification nodule formation in the
control and the differentiated samples after 1 (D1), 7 (D7), 14 (D14) and 21 (D21) days of odontogenic induction. 
Rochester, NY, USA).

Band densitometry was measured using Image $\mathbf{J}$ software (National Institutes of Health); the intensities of the specific protein bands were corrected for equal $\beta$-tubulin loading and were expressed as relative to the intensity of the control sample.

\section{Real Time PCR}

At the end of differentiation, total RNA was extracted by NucleoSpin RNA I (MacheryNagel, Duren, Germany) and quantified using a NanoDrop ${ }^{\circledR}$ ND-1000 UV-Vis Spectropho tometer (Thermo Scientific, Wilmington, DE, USA). One ug of total RNA was reverse transcribed using a high capacity cDNA Reverse Transcription kit (Applied Biosystem, Life Technologies) according to the manufacturer's instructions. The expression of mRNA was analyzed by quantitative Real Time PCR using 7500 Real Time PCR (Applied Biosystem, Life Technologies). For the analysis, the following TaqMan assays (Applied Biosystems, Life Technologies) were used: HS00171962_ml for dentin sialophosphoprotein (DSPP) and Hs00164004_ml for COL1A1 (type 1 collagen alpha 1 chain).

All samples were normalized to glyceraldehyde 3-phosphate dehydrogenase (GAPDH, Hs99999905_m1) expression.

\section{Dentin matrix protein 1 and dentin sialoprotein immunofluorescence}

Thirty thousand cells/mL were seeded on glass slides and induced to odontoblast differentiation as previously described. At the end of each treatment culture, the slides were washed in PBS and fixed with 4\% paraformaldehyde in PBS containing 0.1\% Triton - X 100 (Sigma Aldrich) at $4^{\circ} \mathrm{C}$ for 30 min. After rinsing in PBS, the samples were blocked with $2.5 \%$ bovine serum albumin (BSA) in PBS for 30 min at RT and subsequently incubated at $37^{\circ} \mathrm{C}$ for $2 \mathrm{~h}$ with the following primary antibodies: mouse anti-DMP1 (Santa Cruz Biotechnologies) and goat antiDSP (Santa Cruz Biotechnologies), both diluted 1:50 in blocking reagent. After several washes in PBS /Tween 20, the samples were incubated with secondary antibodies: anti-mouse IgG - Cy3 conjugate and anti-goat IgG FITC conjugate (Sigma Aldrich), all diluted 1:1500 in $\mathrm{PBS}$ at $37^{\circ} \mathrm{C}$ for $1 \mathrm{~h}$. After rinsing in PBS, the samples were counterstained in DAPI, mounted in vectashield medium (Vector Labora tories, Inc, Burlingame, CA, USA) and observed under fluorescence microscopy using an Eclipse E800 Nikon (Nikon, Tokyo, Japan).

\section{Statistical analysis}

Statistical analysis was carried out using GRAPH PAD PRISM 5.0 software (San Diego,
CA, USA) by applying ANOVA and the Dunnett's multiple comparison test. The differences were considered significant at $\mathrm{P}<0.05$.

\section{Results}

\section{Alizarin red staining}

Alizarin red staining was used to evaluate calcium-rich deposits from cells in culture. After $24 \mathrm{~h}$ and after 7 days of odontoblast differentiation, there was no difference between the control and the treated samples (Figure 1). The deposition of calcium was observable after 14 days of treatment, and it notably increased after 21 days of odontogenic induction (Figure 1).

\section{Ultrastructural analysis of human pulp cells differentiated towards odontoblast lineage}

After 1 day of differentiation, the cells showed a fibroblast-shaped morphology (Figure 2A). No protein matrix deposition was detectable. This morphological description was confirmed after 7 days of induction. The cells still showed a fibroblast-shaped morphology and a few fibrillar structures were observable

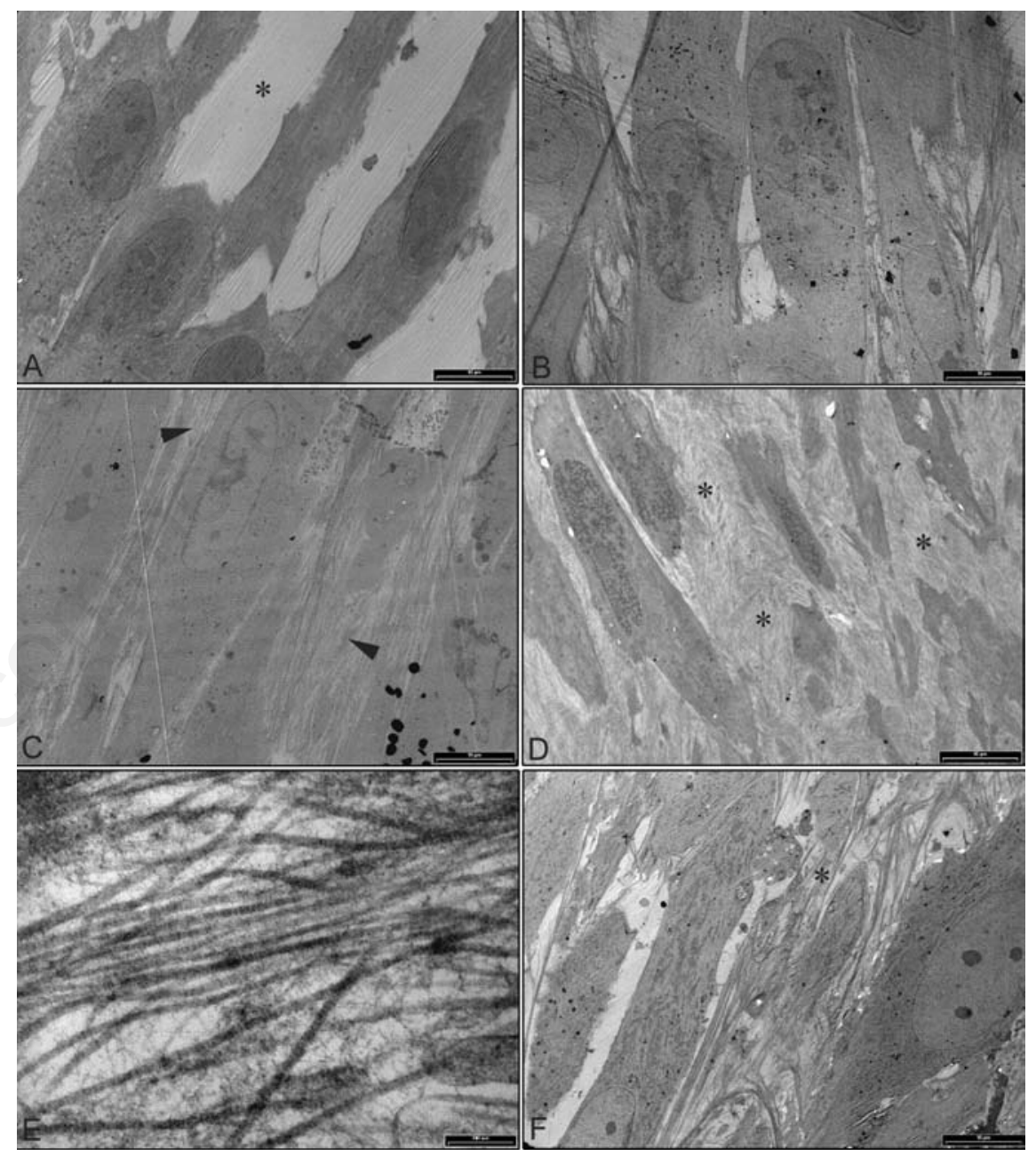

Figure 2. Transmission electron microscopic analysis of hDPCs in vitro induced to odontoblast lineage. A) Human dental pulp cells (hDPCs) after 1 day of treatment; the cells showed a fibroblast-like shape; no protein matrix deposition was detectable $(*)$; scale bar: $10 \mu \mathrm{m}$. B) hDPCs after 7 days (scale bar: $10 \mu \mathrm{m}$ ); and C) hDPCs 14 days (scale bar: 10 $\mu \mathrm{m})$ of odontoblast induction. The amount of fibrillar structures synthesized in the extracellular matrix notably increases with the treatment (arrowhead). D) hDPCs after 21 days of treatment; the extracellular matrix is completely covered by extracellular matrix proteins $\left(^{*}\right)$; scale bar: $10 \mu \mathrm{m}$. E) High magnification of collagen type I fibers; scale bar: 200 $\mathrm{nm}$. F) hDPCs grown for 21 days in cell medium without any odontoblast factors; the cells show a fibroblastic shape but only a few fibers are detected in the extracellular space $\left.{ }^{*}\right)$; scale bar: $10 \mu \mathrm{m}$. 
in the extracellular space (Figure 2B). These structures were presumably related to early protein matrix deposition.

The amount of extracellular proteins increased after 14 days (Figure 2C). By the end of the induction time (21 days), the extracellular space was completely covered by a thick mass of protein matrix (Figure 2D) which appeared to be composed of several parallellyoriented fibers, in which a clear banding structure, resembling type I collagen protein, was detected (Figure 2E). Control cells showed a fibroblast-shaped morphology. The extracellular matrix appeared to be composed of a few thin fibrillar structures (Figure 2F).

\section{Western blot analysis of dentin matrix protein 1 , dentin sialoprotein and type I procollagen $\alpha-1$ protein}

The expression of type I collagen protein was assayed under denaturing conditions by SDS PAGE, and immunodetected by the specific antibody for type I procollagen $\alpha-1$, one of the three chain components of the mature type I collagen protein.
Unexpectedly, the expression of the protein did not notably increase with odontogenic induction. During treatment, a band at 250 $\mathrm{kDa}$ was observable in all the samples (Figure $3 \mathrm{~A}$ ). Densitometry analysis showed a constant signal of the protein in all samples as compared to the control samples (Figure 3B).

Regarding the DSP protein, the bands revealed the presence of a signal at $95 \mathrm{kDa}$, corresponding to the precursor protein, DSPP, from which the DSP derived, and a signal at 37 $\mathrm{kDa}$, corresponding to the $\mathrm{N}$-terminal DSP cleavage product (Figure 3A). Densitometry analysis demonstrated that the expression of the protein was almost constant in all the samples (Figure 3B). Western blot analysis of DMP1 showed the presence of a fragment at $57 \mathrm{kDa}$, corresponding to the C-terminal peptide. Its signal increased from the first day to the last day (Figure 3A), reaching a 2 fold intensity after 21 days, as demonstrated by densitometry analysis (Figure 3B).
mRNA expression of type 1 collagen a1 chain and dentin sialoprotein precursor by Real Time PCR

In order to better quantify the differential expression of type I procollagen 1, DSP and DMP1 and in order to verify whether the expression of the proteins reflected the expression of their mRNA, we carried out a quantitative Real Time PCR for COL1A1, DSPP and DMP1 mRNA.

For the COL1A1 and DSP mRNAs, our results showed a transcription pattern apparently in contrast with their respective protein expression patterns. Expression of the colla1 gene showed the highest level in the early stages of odontogenesis (Figure 4A) while the $d s p p$ gene showed the highest level of expression in the late stages of odontogenic treatment (Figure 4B). After $24 \mathrm{~h}$ and 7 days of odontogenic induction of the cells, relative quantitative results for COL1A1 suggested a 2.5 fold increase of the transcript as compared to the control samples while, in all the other samples, the expression of COL1A1 mRNA was comparable to the control samples (Figure 4A).
A

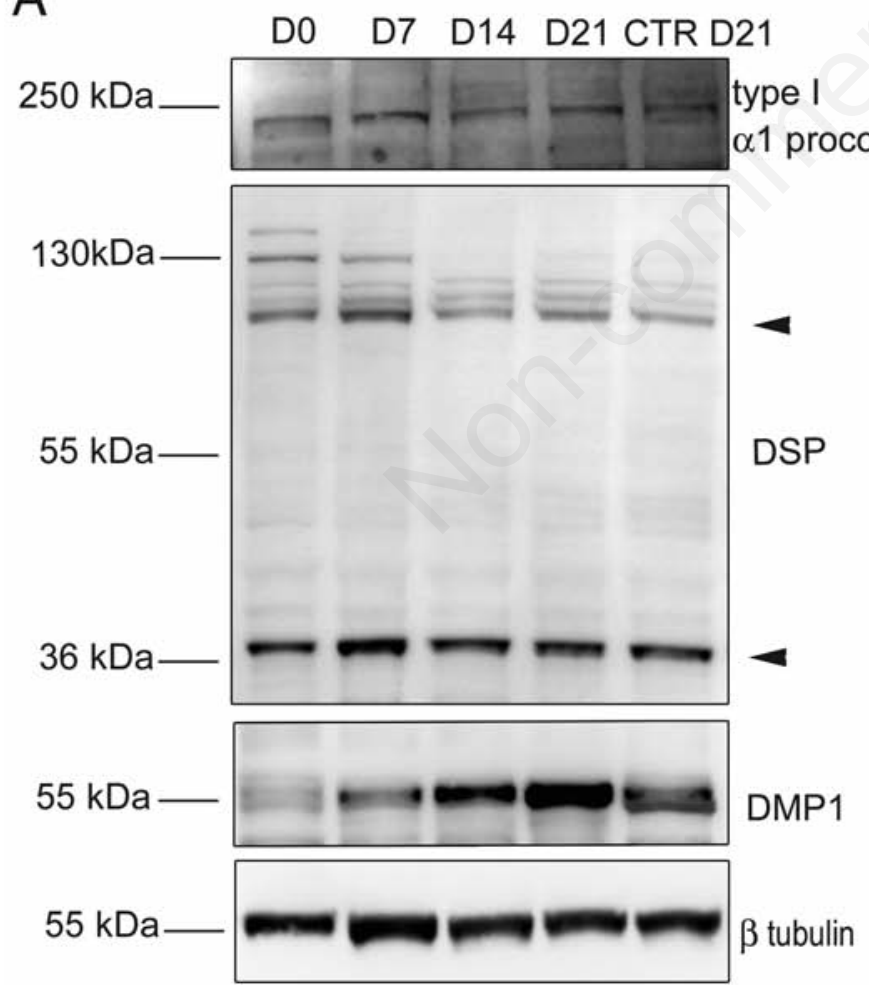

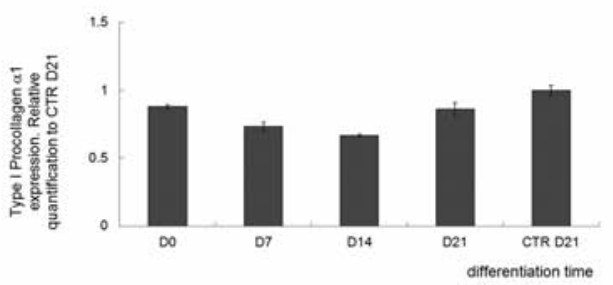
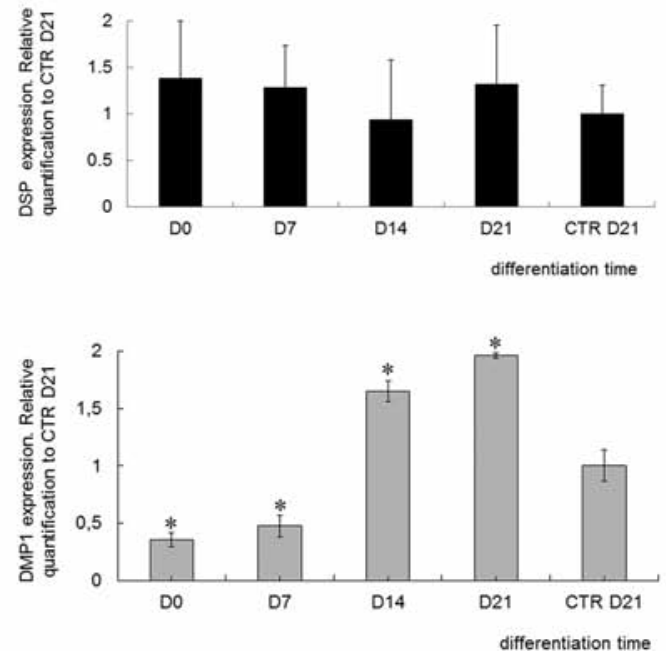

Figure 3. A) Protein extracts were separated by 4-12\% SDS PAGE, and western blot analysis was carried out for type I procollagen $\alpha 1$, DSP and DMP1; $\beta$ tubulin was used as a loading control. B) Densitometry of type I procollagen $\alpha 1$, DSP and DMP1 western blot bands; intensities of the specific protein bands were calculated as relative optical density $v$ s D21 control samples (D21 CTR) and corrected for equal $\beta$-tubulin loading; asterisk represents a significant difference from the control sample at $P<0.05$. 
In the early stages of odontogenic differentiation, comparable levels of DSPP mRNA were detected in the control samples (Figure 4B). Odontogenic induction significantly enhanced $d s p p$ gene expression at 7 and 14 days, in which the levels of DSPP mRNA were almost 9 fold higher than the control samples (Figure 4B). The dmpl gene expression showed a higher level of mRNA after 21 days of treatment, resembling the corresponding DMP1 protein expression (Figure 4C).

\section{Immunofluorescence localization of} dentin matrix protein 1 and dentin sialoprotein

After 7 days of odontogenic induction, the HDPs showed a low signal corresponding to DMP1 expression, manly localized in the nuclear area (Figure 5). After 14 and 21 days, the fluorescence signal was localized in both the nuclear and the cytoplasmic regions (Figure 5). At day 21 of treatment, the control samples showed a weak fluorescence signal in both the nuclear and the cytoplasmic areas (Figure 5).

The DSP expression showed a very similar localization. After 7 days of odontogenic treatment, the fluorescence signal was mainly localized in the nuclear region while, at days 14 and 21 of treatment, the protein signal had shifted to the cytoplasmic region (Figure 6). The control samples showed a weak signal, mainly localized in the cytoplasm (Figure 6).

\section{Discussion}

During the last decade, awareness of the necessity of finding a repetitive model for studying human odontoblast differentiation during tooth embryonic development, and during reparative and reactionary dentin synthesis, was noted, and numerous scientific studies regarding in vitro odontoblast differentiation were published..$^{1,14,16,18-21}$ Odontoblasts are post-mitotic cells unable to proliferate, which makes their cultivation by traditional cell culture systems unsuccessful. Some authors have suggested culture methods for human odontoblasts based on the dissected crowns of molars, in which the pulp was removed and the odontoblast layer, attached to the walls of the pulp chamber, was cultured in cell medium..$^{18}$ Melin and colleagues ${ }^{21}$ proposed a dental pulp cell culture on human tooth slices. Even though both methods allowed studying the behavior of human odontoblasts, they were based on mature cells, thus not representing a good model for evaluating the mechanisms involved in odontogenic differentiation.

In the present study, the biochemical and biomolecular assays of DMP1, DSP and type I collagen validated the proposed in vitro model for studying odontoblast cell differentiation from hDPCs. Moreover, this model may allow studies to elucidate the signalling pathway involved in tertiary human dentin formation under physiological and pathological conditions. Normal dental pulp contains numerous cell populations, including fibroblasts, immune cells, and latent or dormant pulp stem cells. ${ }^{2,22}$
Following deep dentin injury, newly generated odontoblast-like cells differentiate from progenitor cells within the pulp and secrete a reparative dentin matrix. ${ }^{2}$ It is unclear which subpopulation of the pulp is responsible for the synthesis of the reparative dentin. The presence of adult stem cells in the pulp has led to the hypothesis that the reparative progenitor cells are stem cells, but this has not been fully demonstrated. ${ }^{23,24}$ We developed an odonto-
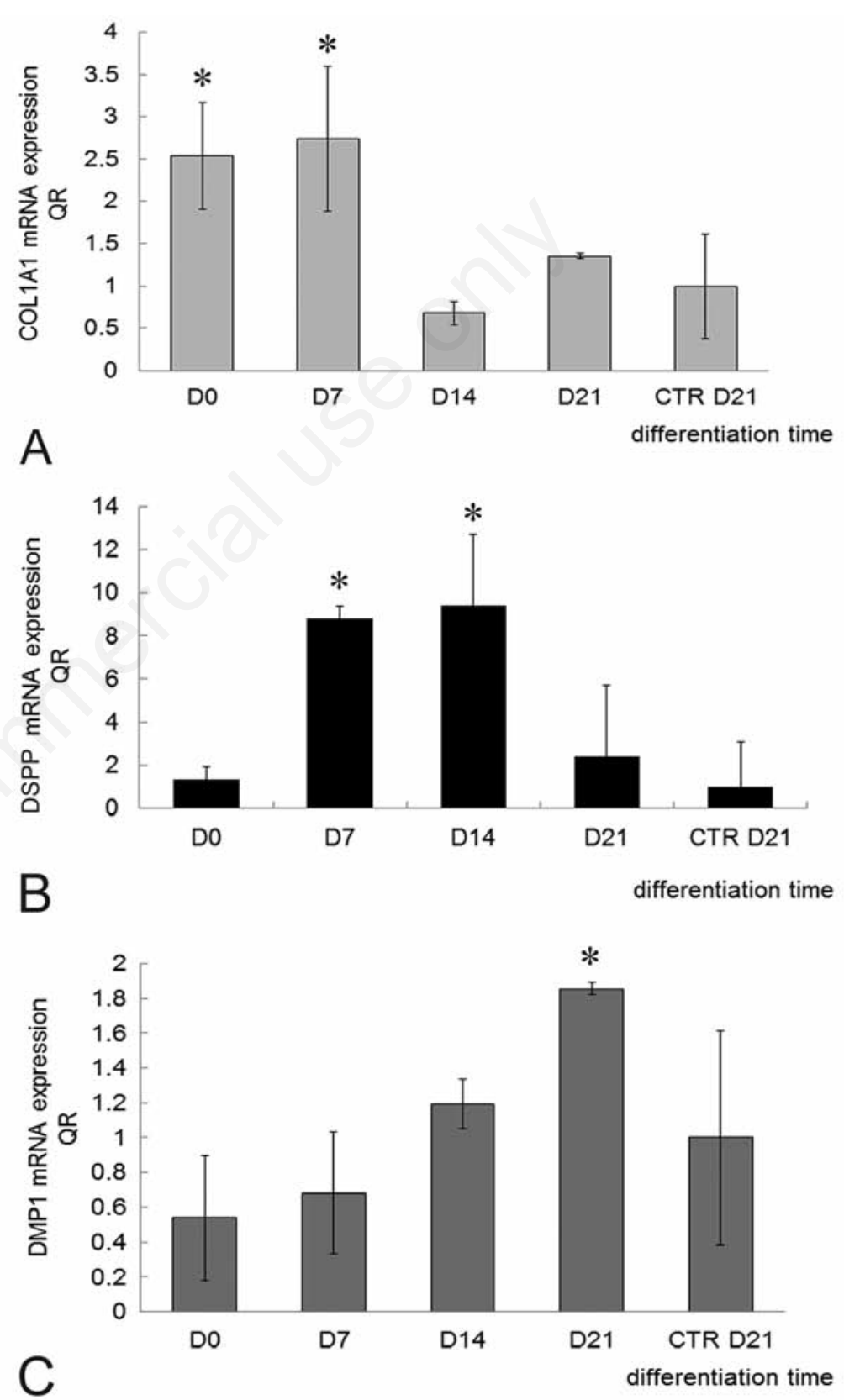

Figure 4. Odontoblastic markers COL1A1 (A), DSPP (B) and DMP1 (C) mRNA expression during the odontogenic differentiation were quantified by Real Time PCR. collal gene expression is higher in the early stages of differentiation while $d s p p$ gene expression is higher in the late stages of treatment. The $d m p 1$ gene showed an elevated mRNA expression in the late stage of odontoblast differentiation; asterisk represents a significant difference from the control sample at $\mathrm{P}<0.05$ 
blast model based on hDPCs, obtained from pulp explants without any specific identification or separation of the subpopulations. The hDPCs were differentiated in vitro by cell medium supplemented with a cocktail of odontogenic factors (dexamethasone, $\beta \mathrm{GP}$, ascorbic acid) whose concentrations have been established by previous scientific reports and to which we added TGF- $\beta 1^{1,14,21,24,25}$ Dexamethasone, $\beta$ GP and ascorbic acid represent the factors which are, for the most part, successfully utilized for in vitro osteogenic differentiation from mesenchymal stem cells..$^{26,27}$

We added TGF- $\beta 1$ to the cocktail medium after performing different experiments using only $\beta \mathrm{GP}$, ascorbic acid and dexamethasone, in which significant effects on odontoblast differentiation were not obtained (data not shown). Obtaining better results with the addition of TGF- $\beta 1$ indicated that a synergic combination of osteogenic/odontogenic factors with TGF- $\beta 1$ is more effective in promoting the faster and more effective differentiation of pulp cells. The TGF- $\beta 1$ belongs to a large family of GFs, which play important roles in tooth development and dental tissue repair., 9,22,28,29

Our results demonstrated that cell medium, supplemented with dexamethasone, $\beta$ GP, ascorbic acid and TGF- $\beta 1$, induced mineral deposition and enhanced the expression of odontogenic markers, such as DSP and DMP. These results are in agreement with previous data in which the upregulation of DSP, BSP and the TGF-betal receptor induced by TGFbetal treatment was investigated on reparative dentin. ${ }^{30}$ Unda and colleagues ${ }^{31}$ demonstrated the synergic effect of TGF-betal in combination with FGF1 and FGF2, in inducing polarization and the functional differentiation of preodontoblasts in mouse dental papillae cultured in vitro. To fully demonstrate the odontoblast phenotype, transmission electron microscopy analysis of the cell morphology and dentin extracellular matrix, and the expression of odontogenic markers, such as type I collagen, DSP and DMP1, were assayed by Western blot analysis. Electron micrographs showed a few fibroblast-like cells at the beginning of cell induction ( $24 \mathrm{~h}$ ) with no extracellular matrix. After 14 days, a few fibrillar structures in the extracellular area were detected, connected with extracellular dentin proteins. After 21 days of induced odontogenesis, the extracellular space was completely covered by thick fibers in which the banding structure of type I collagen was detected. The synthesis and deposition of irregularly arranged dentin collagen fibers had already been demonstrated in hDPCs differentiated for 3 weeks with ascorbic acid and high concentrations of $\beta$ GP and fetal bovine serum. ${ }^{1}$ Since the presence of type I collagen is not sufficient for demonstrating the odontogenic phenotype, the expression of DSP and DMP1 were also investigated. Dentin SP, DPP and DMP1 have long been considered unique odontogenic markers. However, it is now well established that several non-mineralized tissues, as well as bone tissue, express these markers, even if in minor quantities with respect to the dentinal marker. ${ }^{32-35}$

Western blot analysis showed a constant expression of type I collagen protein during treatment while DMP1 expression was higher at the end of treatment; DSP expression showed the cleavage of the precursor protein $(95 \mathrm{kDa})$ and a significant level of the active protein $(37 \mathrm{kDa})$, which remained constant for the entire differentiation treatment. To better quantify the difference of expression of type I collagen, DMP1 and DSP during the odontoblast differentiation treatment, a Real Time PCR was carried out. COL1A1 mRNA showed a temporal transcription and reached high levels of expression during the early stages of differentiation. Type I collagen protein is one of the first extracellular matrix components to be expressed, forming a template for the controlled deposition of calcium phosphate. ${ }^{3}$ Regarding the DMP1, an increase in the signal is detectable after 14 days of odontogenic

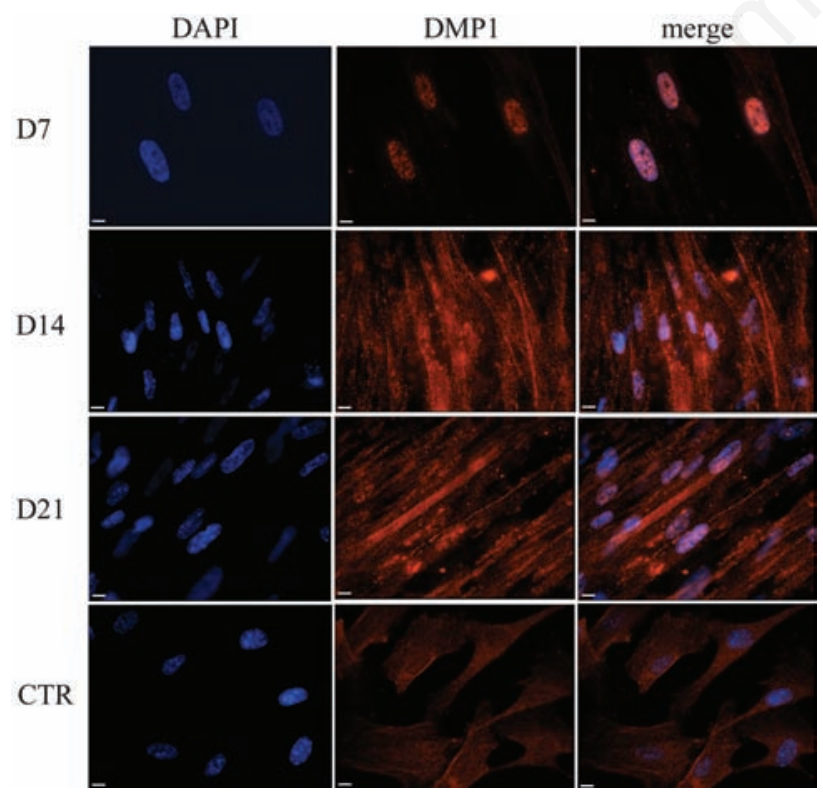

Figure 5. Immunofluorescence localization of DMP1 during odontoblast differentiation; CY3-conjugated antibody was used to detect the localization of the protein (red signal); all samples were counterstained with DAPI; after 7 days of treatment, DMP1 is mainly localized in the nucleus; by the end of the odontogenic induction, the signal is localized both in the nucleus and the cytoplasm; the control samples do not show any significant protein signal. Magnification: $600 x$; scale bar: $10 \mu \mathrm{m}$.

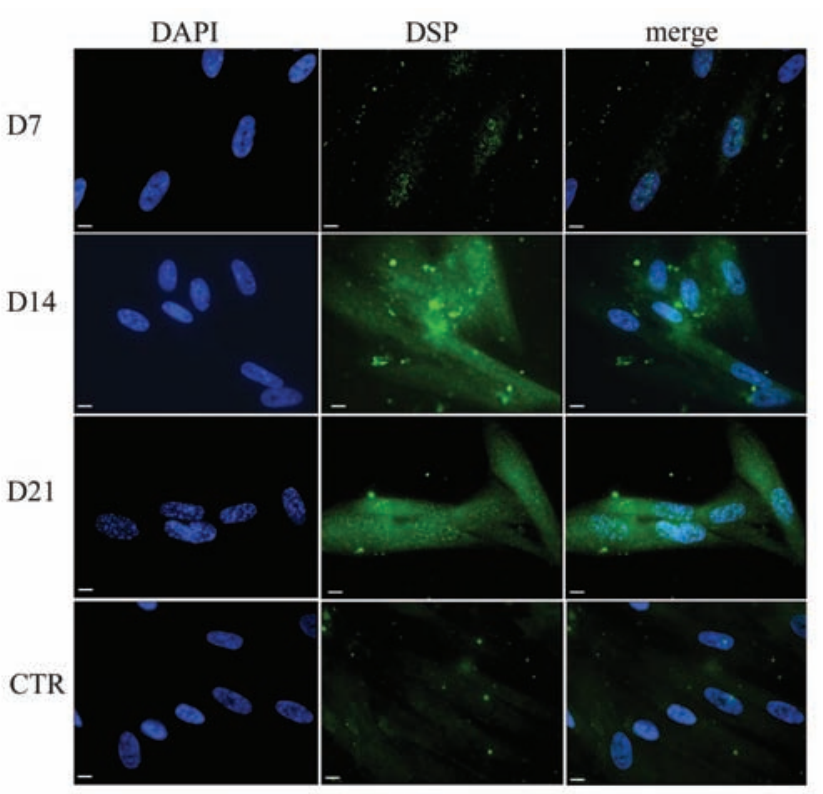

Figure 6. Immunofluorescence localization of the DSP during odontoblast differentiation; FITC-conjugated antibody was used to detect the localization of the protein (green signal); all samples were counterstained with DAPI; after 7 days of treatment, the DSP is localized solely in the nucleus; in the middle and at the end of the odontogenic induction, the protein signal is localized in both the nucleus and the cytoplasm; the control samples do not show any significant protein signal. Magnification: 600x; scale bar: $100 \mu \mathrm{m}$. 
induction, reaching a maximum level after 21 days. Our results are in agreement with a temporal expression of DMP1 ${ }^{3,7}$ in which an elevated in vivo expression of the protein is detectable in odontoblasts at the beginning of mineral matrix deposition. In our study, mineralization started after 14 days of odontogenic induction, as demonstrated by the alizarin red staining. On the other hand, the $d s p p$ gene showed a gradual increase in its mRNA, reaching its highest levels after 7 and 14 days of induction. The DSPP mRNA codified for the DSPP protein, a large parental protein which subsequently underwent cleavage to generate three products: DSP, DPP and dentin glycoprotein (DGP). ${ }^{36}$ Increasing levels of DSPP mRNA at day 14 indicated an early and constant transcription of the dspp gene in odontoblast differentiation. $^{3}$ The lack of correspondence between $d s p p$ gene expression and DSP protein expression could be explained by the production of the DSPP large protein which underwent very rapid cleavage, ${ }^{36}$ releasing major amounts of DSP products. In our study, during in vitro odontoblast induction, DMP1 was initially expressed and localized only in the nucleus of HDPs. By the end of the treatment, a strong protein signal was detectable in the cytoplasm and in the nucleus of the HDPs. The translocation of DMP1 from the nucleus to the cytoplasm could be related to the in vitro induction of odontoblast-like cell differentiation. It has been demonstrated that, in undifferentiated osteoblasts, DMP1 is transported to the nucleus where it acts to regulate the transcription of genes involved in matrix mineralization. ${ }^{37}$ During the early phase of osteoblast maturation, $\mathrm{Ca}^{2+}$ surges into the nucleus from the cytoplasm, triggering the phosphorylation of DMP1 by a nuclear isoform of casein kinase II. This phosphorylated DMP1 is then transported into the extracellular matrix where it regulates nucleation of hydroxyapatite..$^{38,39}$ These data were confirmed by the alizarin stain results in which a mineral deposition was detectable after 14 days of odontogenic induction. During dentinogenesis, DSPP is proteolytically cleaved into two subunits, generating DSP and DPP. Dentin phosphoprotein is thought to play a role during the nucleation of calcium phosphate while DSP has little or no effect on mineralization. ${ }^{40}$ Its real function remains unclear. Our results showed the presence of the DSP after 7 days of differentiation; it was found to be located solely in the nucleus. During treatment, the protein signal translocated from the nucleus to the cytoplasm. According to the scientific literature, during dentinogenesis, DSP localizes predominantly in the dentinal tubules at the site of the peritubular dentin. ${ }^{39}$ It has recently been demonstrated that recombinant DSP markedly increases alkaline phosphatase (ALP) activity, calcium nodule formation and bone morphogenetic protein-2 (BMP2) expression in HDPs ${ }^{41}$ suggesting a pivotal role of DSP during dentin deposition. We hypothesized that the nuclear localization of DSP could be connected to the regulation of the genes involved in the dental matrix synthesis.

Based on the reported findings, this model can be useful in establishing an in vitro protocol for human odontoblast differentiation which simulates the reparative dentin processes. The morphological, biochemical and biomolecular techniques combined qualitative and quantitative assays, thus providing a complete panel of the expression of the predominant dentin extracellular proteins.

\section{References}

1. Couble ML, Farges JC, Bleicher F, PerratMabillon PB, Boudeulle M, Magloire H. Odontoblast differentiation of human dental pulp cells in explants cultures. Calcif Tissue 2000;66:129-38.

2. Goldberg M, Smith AJ. Cells and extracellular matrices of dentin and pulp: a biological basis for repair and tissue engineering. Crit Rev Oral Biol Med 2004;15:13-27.

3. Arana-Chavez VE, Massa LF. Odontoblasts: the cells forming and maintaining dentine. Intern. J Biochem Cell Biol 2004;36:1367-73.

4. Hao J, Zou B, Narayanan K, George A. Differential expression patterns of the dentin matrix proteins during mineralized tissue formation. Bone 2004;34:921-32.

5. Goldberg M, Septier D, Lecolle S, Chardin H, Quintana MA, Acevedo AC, et al. Dental mineralization. Int J Dev Biol 1995;39:93110.

6. Butler WT. Dentin matrix proteins and dentinogenesis. Connect Tissue Res 1995; 33:59-65.

7. Massa FL, Ramachandran A, George A, Arana-Chavez VE. Developmental appearance of dentin matrix protein 1 during the early dentinogenesis in rat molars as identified by high resolution immunocytochemistry. Histochem Cell Biol 2005;124: 197-205.

8. Martinez EF, Herdy Da Silva LA, Furuse C, Soares De Araujo N, Cavalcanti De Araujo V. Dentin matrix protein 1 (DMP1) expression in developing human teeth. Braz Dent J 2009;20:365-9.

9. Smith AJ, Matthews JB, Hall RC. Transforming growth factor - beta 1 (TGF beta 1) in dentin matrix. Ligand activation and receptor expression. Eur J Oral Sci 1998;106:179-84.

10. Mitsiadis TA, Rahiotis C. Parallels between tooth development and repair: conserved molecular mechanisms following carious and dental injuries. J Dent Res 2004;83: 896-902.

11. Smith AJ, Lesot H. Induction and regulation of crown dentinogenesis: embryonic events as a template for dental tissue repair? Crit Rev Oral Biol Med 2011;12: 425-37.

12. Bègue-Kirn C, Smith AJ, Loriot $M$, Kupferle C, Ruch J, Lesot H. Comparative analysis of TGF s, BMPs, IGF1, msxs, fibronectin, osteonectin and bone sialoprotein gene expression during normal and in vitro-induced odontoblast differentiation. Int J Dev Biol 1994;38:405-20.

13. Lesot H, Lisi S, Peterkova R, Peterka M, Mitolo V, Ruch JV. Epigenetic signals during odontoblast differentiation. Adv Dent Res 2001;15:8-13.

14. About I, Bottero MJ, De Denato P, Camps J, Franquin JC, Mitsiadis TA. Human dentin production in vitro. Exp Cell Res 2000;258: 33-41.

15. Shi Y, Massague J. Mechanisms of TGFbeta signaling from cell membrane to the nucleus. Cell 2003;113:685-700.

16. Riccio M, Resca E, Maraldi T, Pisciotta A, Ferrari A, Bruzzesi G, et al. Human dental pulp stem cells produce mineralized matrix in 2D and 3D cultures. Eur $\mathrm{J}$ Histochem 2010;54:e46.

17. Jiang D, Xu C, Li Z, Zhang Y, Han F, Jiang Z. Protective action of hepatocyte growth factor on transforming growth factor beta1-induced alpha-smooth muscle actin and extracellular matrix in cultured human peritoneal fibroblasts. Med Sci Monit 2010;16:250-4.

18. Tjäderhane L, Salo T, Larjava H, Larmas M, Overall CM. A novel organ culture method to study the function of human odontobalsts in vitro: gelatinase expression by odontobalsts is differentially regulated by TGFß1. J Dent Res 1998;77:1486-96.

19. Li Y, Lu X, Sun X, Bai S, Li S, Shi J. Odontoblast-like cell differentiation and dentin formation induced with TGFbl. Arc Oral Biol 2011;56:1221-9.

20. Magne D, Bluteau G, Lopez-Cazaux S, Weiss P, Pilet P, Ritchie H, et al. Development of an odontoblast in vitro model to study dentin mineralization. Connect Tissue Res 2004;45:101-8.

21. Melin M, Joffre-Romeas A, Farges JC, Couble ML, Magloire H, Bleicher F. Effects of TGF $\beta 1$ on dental pulp cells in cultured human tooth slices. J Dent Res 2000;79: 1689-96.

22. Goldberg M, Farges JC, Lacerda-Pinheiro $\mathrm{S}$, Six N, Jegat N, Decup F, et al. Inflammatory and immunological aspects of dental pulp repair. Pharmacol Res 
2008;58:137-47.

23. About I. Dentin regeneration in vitro: the pivotal role of supportive cells. Adv Dent Res 2011;23:320-4.

24. Lee JH, Lee DS, Choung HW, Shon W-J, Seo B-M, Lee EH, et al. Odontogenic differentiation of human dental pulp stem cells induced by preameloblast-derived factors. Biomaterials 2011;32:9696-9706.

25. Takeda T, Tezuka Y, Horiuchi M, Hosono K, Iida K, Hatakeyama D, et al. Characterization of dental pulp stem cells of human tooth germs. J Dent Res 2008; 87:676-81.

26. Jaiswal N, Haynesworth SE, Caplan AI, Bruder SP. Osteogenic differentiation of purified, culture-expanded human mesenchymal stem cells in vitro. J Cell Biochem 1997;64:295-312.

27. Teti G, Cavallo C, Grigolo B, Giannini S, Facchini A, Mazzotti A, et al. Ultrastructural analysis of human bone marrow mesenchymal stem cells during in vitro osteogenesis and chondrogenesis. Microsc Res Tech 2012;75:596-604.

28. Bègue-Kirn C, Smith, AJ, Ruch JY, Wozney JM, Purchio A, Hartmann D, et al. Effects of dentin proteins, transforming growth factor beta 1 (TGF beta 1) and bone morphogenetic protein 2 (BMP2) on the differentiation of odontoblast in vitro. Int J Dev Biol 1992;36:491-503.
29. Roberts AB, Heine UI, Flanders KC, Sporn MB. Transforming growth factor-beta. Major role in regulation of extracellular matrix. Ann N Y Acad Sci 1990;580:225-32.

30. Hwang Y, Hwang I, Oh W, Park J, Lee D, Son H. Influence of TGF-b1 on the expression of BSP, DSP, TGF b1 receptor and Smab proteins during reparative dentinogenesis. J Mol Hist 2008;39:153-60.

31. Unda FJ, Martin A, Hernandez C, PerezNanclares G, Hilario, Arechaga J. FGFs-1 and -2 , and TGFb1 as inductive signals modulating in vitro odontoblast differentiation. Adv Dent Res 2001;15:34-8.

32. Qin C, Brunn Jc, Cadena E, Ridall A, Tsujigiwa H, Nagatsuka $H$, et al. The expression of dentin sialophosphoprotein gene in bone. J Dent Res 2002;81:392-4.

33. Ogbureke KU, Fisher LW. SIBLING expression patterns in duct epithelia reflect the degree of metabolic activity. J Histochem Cytochem 2007;55:403-9.

34. Orsini G, Ruggeri A, Mazzoni A, Nato F, Falconi M, Putignano A, et al. Immunohistochemical localization of dentin matrix protein 1 in human dentin. Eur $\mathrm{J}$ Histochem 2008;52:215-20.

35. Orsini G, Ruggeri A, Mazzoni A, Nato F, Manzoli L, Putignano A, et al. A review of the nature, role, and functions of dentin non-collagenous proteins. Part I: proteoglycans and glycoproteins. Endodontic
Topics 2012;21:1-18.

36. Yamakoshi Y, Hu JC, Iwata T, Kobayashi K, Fukae M, Simmer JP. Dentin sialophosphoprotein is processed by MMP2 and MMP20 in vitro and in vivo. $\mathrm{J}$ Biol Chem 2006;281:38235-43.

37. Narayanan K, Ramachandran A, Hao J, He G, Park KW, Cho M, et al. Dual functional roles of dentin matrix protein 1 . Implications in biomineralization and gene transcription by activation of intracellular Ca2+ store. J Biol Chem 2003;278: 17500 8.

38. He G, George A. Dentin matrix protein 1 immobilized on type I collagen fibrils facilitates apatite deposition in vitro. J Biol Chem 2004;279:11649-56.

39. Hao J, Ramachandran A, George A. Temporal and spatial localization of the dentin matrix proteins during dentin biomineralization. J Histochem Cytochem 2009;57:227-37.

40. Boskey A, Spevak L, Tan M, Doty SB, Butler WT. Dentin sialoprotein (DSP) has limited effects on in vitro apatite formation and growth. Calcif Tissue Int 2000;67:472-8.

41. Lee SY, Kim SY, Park SH, Kim JJ, Jang JH, Kim EC. Effects of recombinant dentin sialoprotein in dental pulp cells. J Dent Res 2012;91:407-12. 